\section{Direct Photochemical \\ cis-trans Isomerization with \\ 185 nm Radiation: \\ A Facile Preparation of cis-Di-tert-butylethylene}

Waldemar Adam*

Department of Chemistry,

University of Puerto Rico, Rio Piedras,

Puerto Rico 00931 (USA) and Institute of

Organic Chemistry, University of Würzburg,

D-8700 Würzburg

Faris Yany

Department of Natural Sciences,

Interamerican University, Hato Rey,

Puerto Rico 00919, USA

Z. Naturforsch. 36 b, 658 (1981);

received February 3, 1981

cis-trans Isomerization,

$185 \mathrm{~nm}$ Photochemistry, $\pi-\pi^{*}$ Excitation,

Steric Congestion, Olefin Synthesis

On irradiation of trans-di-tert-butylethylene at $185 \mathrm{~nm}$ in pentane the sterically congested cis-isomer was formed in $c a .40 \%$. This $\pi-\pi^{*}$ excitation constitutes a convenient, direct method for the preparation of such usually difficult to prepare olefins.

Triplet ketone sensitization is one of the common methods for the cis-trans isomerization of olefins [1]. However, $(2+2)$-cycloaddition between the excited ketone and olefin can be a serious side reaction [2]. Moreover, sterically congested olefins such as transdi-tert-butylethylene (1 a) cannot be isomerized via such indirect photochemical methods into the cisisomer (1 b).<smiles>CC(C)CC=CCBr</smiles>

(1a)<smiles>CC(C)CC=CCBr</smiles>

(1 b)
Recently it has been shown [3] that $185 \mathrm{~nm}$ radiation is effective in directly isomerizing ciscyclooctene into its trans-isomer. The formation of this strained cycloalkene was the result of $\pi-\pi^{*}$ excitation. Consequently, we expected that the isomerization of trans-(1) into cis-(1) b) could be effected through such direct $\pi \rightarrow \pi^{*}$ excitation with $185 \mathrm{~nm}$. Indeed, irradiation of a ca. $0.15 \mathrm{M}$ solution of $1 \mathrm{a}$ in pentane (Baker Photrex) at $185 \mathrm{~nm}$, using a $50 \mathrm{~W}$ mercury resonance lamp as light source, led within $10 \mathrm{~h}$ to a photostationary state of $c a .40 \%$ cis-isomer (1) b), as monitored by gas chromatography. Fractional distillation on a $15 \mathrm{~cm}$ spinning band column afforded the pure 1b, b.p. $144^{\circ} \mathrm{C} /$ 760 Torr (lit. [4] b.p. $144{ }^{\circ} \mathrm{C} / 748$ Torr); ${ }^{1} \mathrm{H}$ NMR $\left(\mathrm{CCl}_{4}, \mathrm{TMS}\right) \delta(\mathrm{ppm}) 0.95(\mathrm{~s}, 18 \mathrm{H})$ and $5.10(\mathrm{~s}, 2 \mathrm{H})$.

Compared with the existing synthetic methods of preparing such sterically congested cis-olefins, e.g. cis-1 b was previously prepared via the classical but cumbersome route using as last step cis-hydrogenation of di-tert-butylacetylene [4], the convenience of the direct photochemical isomerization with $185 \mathrm{~nm}$ radiation is clearly evident. It appears, therefore, that this novel and facile process is of potential synthetic utility.

Acknowledgements are made to the Donors of the Petroleum Research Fund, administered by the American Chemical Society, the National Science Foundation, the National Institutes of Health, the German Forschungsgemeinschaft and the Fonds der Chemischen Industrie for generous financial support. We thank Dr. R. Srinivasan for getting us started in $185 \mathrm{~nm}$ photochemistry.
* Reprint requests to Prof. Dr. W. Adam. 0340-5087/81/0500-0658/\$01.00/0

[1] J. Saltiel and J. L. Charlton, in P. de Mayo (ed.): Rearrangements in Ground and Excited States, Academic Press, New York 1980, Vol. 3, Chapter 14; H. Meier, Photochemie I, in HoubenWeyl's Methoden der Organischen Chemie,
Georg Thieme, Stuttgart 1976; D. O. Cowan and R. L. Drisko, Elements of Organic Photochemistry, Plenum Press, New York 1976, Chapter 9.

[2] N. C. Yang, J. I. Cohen, and A. Shani, J. Am. Chem. Soc. 90, 3264 (1968).

[3] R. Srinivasan, J. A. Ors, K. H. Brown, T. Baum, L. S. White, and A. R. Rossi, J. Am. Chem. Soc. 102, 5297 (1980).

[4] G. F. Henion and T. F. Banigan, J. Am. Chem. Soc. 68, 1202 (1946). 